\title{
Publicização da gestâo hospitalar no SUS: reemergência das Organizaçôes Sociais de Saúde
}

\section{I ${ }^{1}$ Manoela Cerqueira Reis, ${ }^{2}$ Thereza Christina Bahia Coelho I}

Resumo: O Estado da Bahia foi pioneiro na privatização da gestão hospitalar por meio de uma política de incentivo às Organizaçôes Sociais de Saúde (OSS), sob o discurso da eficiência. A rapidez de penetração do setor privado na esfera pública, com alteração da noção de democracia e interesse público, tem sido globalmente observada. A análise da incorporação das OSS à gestão dos hospitais estaduais baianos, proposta por este estudo de caso, utilizou documentos disponíveis em sites de domínio público e entrevistas com gestores de hospitais "publicizados" e da Secretaria Estadual de Saúde da Bahia (Sesab). A interpretação dos resultados sob o filtro de categorias históricas e analítico-operacionais evidenciou a ascensão das terceirizaçôes, a partir de 1996, e a incorporação das OSS à cena hospitalar baiana, a partir de 2005, pari passu com o afrouxamento do Conselho Estadual de Saúde e o avivamento do discurso de maior resolutividade das OSS, que seriam "quase como o Estado". Para afinarse com o novo discurso governamental, empresas antes terceirizadas mudaram sua personalidade jurídica para OSS, demonstrando um processo de privatização disfarçada, no bojo de um governo que sustentou discurso contrário a essa prática, antagônica aos princípios de seguridade da saúde, expressos na Constituição Federal.

> Palavras-chave: gestão em saúde; gestão hospitalar; terceirização.

\author{
1 Departamento de Saúde, \\ Universidade Estadual de Feira de \\ Santana. Feira de Santana-BA \\ Brasil (enf.manoela@gmail.com). \\ ORCID: 0000-0002-6674-0744 \\ ${ }^{2}$ Departamento de Saúde, \\ Universidade Estadual de Feira de \\ Santana. Feira de Santana-BA, \\ Brasil (tcuide@yahoo.com.br). \\ ORCID: 0000-0003-4787-4103
}

Recebido em: 17/04/2017 Revisado em: 05/08/2018 Aprovado em: 08/10/2018 


\section{Introdução}

$\mathrm{Na}$ década de 1990, com a incorporação do repertório da escolha racional sob as vestes do novo institucionalismo, operada pelo governo de Fernando Henrique Cardoso (FHC), o Brasil iniciou a concretização das propostas reformadoras, estabelecidas pelo Plano Diretor da Reforma do Aparelho do Estado (PDRAE). Com o intuito de diminuir a responsabilidade do Estado na execuçáo direta de serviços e tornar mais "robusto" o seu papel de promotor e regulador, o PDRAE estabeleceu o Programa Nacional de Publicização a fim de transferir a gestão de serviços públicos para entidades privadas sem, necessariamente, transferir a sua propriedade (MELO et al., 2009; COSTA, 1998; BRASIL, 1995; ANDREWS; KOUZMIN, 1998).

O processo de "publicizaçáo" ganhou relevância no cenário hospitalar em meio à crise do setor que acometia todo o país: faltava gestáo capaz, eficiente, moderna e humana, muitas vezes, com alto custo e baixo resultado (IBANEEZ; VECINA NETO, 2016). Desse modo, o Estado passara a se desresponsabilizar pela execução direta das atividades administrativas, no setor hospitalar, culminando com o reconhecimento e a valorização de um espaço público não estatal, como ator na provisão de serviços públicos, compreendendo, portanto, as novas modalidades de Gestão Indireta (GI) (GUIMARÁES et al., 2004).

O avanço do setor privado na gestão e prestação de serviços públicos, entretanto, não foi um fenômeno local, nem mesmo nacional, fazendo parte de um processo internacional de re-estruturação do capital que atinge os países globalmente a partir de reformas setoriais denominadas por alguns autores (WARING, 2015) como "diáspora", numa tentativa acrítica de levar para o campo "neutro" das relaçóes culturais um processo desencadeado pela Nova Gestão Pública (New Public Management-NPM), que não cumpriu com os objetivos de melhora da eficiência do National Health System (NHS), segundo Simonet (2013). Nesse contexto, a criação de modelos híbridos afetaria os desempenhos dos serviços, modificaria aspectos culturais do campo da saúde, produziria iniquidades no acesso e colocaria em xeque a própria dicotomia público-privado ao produzir um borramento nas interrelaçóes entre interesse privado e bem público, que passam a funcionar sob a égide discursiva do mercado.

Mais do que isso, o que se tem observado desde o início do novo ciclo neoliberal, segundo Kamat (2004), seria a privatização da noção de interesse 
público e reinvenção da democracia no atendimento aos interesses do capital. Do ponto de vista do impacto econômico dessa nova cultura, Reevesa et al. (2014), ao analisarem o padrão de gastos com saúde de 27 países da União Europeia, entre 1995 e 2011, encontraram ausência de relação direta com o desempenho do Produto Interno bruto (PIB), relação esta usada como justificativa para redução de gastos. Em verdade, tal redução foi significativa nos países que contraíram empréstimos com instituiçôes financeiras internacionais e naqueles governados por partidos de orientação neoliberal.

Mas não apenas os países endividados se colocam à mercê da ganância privada. Svallfors e Tyllström (2017) revelam como em países com sistemas de bem-estar social bem consolidados, tal qual a Suécia, empresas privadas lucrativas vêm assumindo rapidamente a oferta de serviços de saúde e fazendo proteção de mercado graças à "resiliência" da sociedade, que tende a não levá-las a sério, permitindo sua ação estratégica na organização dos atores, percepções e comunicação, criação de fatos e pavimentação de terreno para a mobilização, sedução de entidades de saúde e trabalhadores, produção de padrôes e normas, abertura e fechamento de canais, manipulação de policy makers e exaltação da "transparência" para melhor preservação dos seus particulares interesses.

Também na América Latina, o neoliberalismo provocou enorme impacto social, com aumento das iniquidades na distribuição de renda e severa piora dos indicadores de saúde, que Laurell (2015) denominou "privatização dos lucros e socialização dos prejuízos”.

Ainda em meio ao debate sobre as reformas estruturais, O’Laughlin (2016) chama a atenção para o modo como as desigualdades em saúde ficam embutidas na "redefinição do acesso universal aos cuidados de saúde e acesso universal à cobertura de seguro; na canalização da medicina científica para a pesquisa de inovaçôes de commodities que atrairão ricos consumidores; na limitação dos cuidados de saúde públicos prestados a pobres e desprovidos; e no desmantelamento dos sistemas de saúde pública que vinculam cuidado a prevenção” (p.705).

Voltando ao plano nacional, o Estado da Bahia foi um dos primeiros na instituição de novas modalidades de privatização da gestâo por meio da Lei no $7.027 / 97$, que criou o Programa de Incentivo às Organizaçóes Sociais (PIOS), sob o discurso de maior eficiência e qualidade dos serviços prestados à população. Nesse caso, o Estado transferiria a administração hospitalar para entidades privadas, sem fins lucrativos: 
as Organizaçôes Sociais de Saúde (OSS). Entretanto, por mudanças no cenário político, a gestáo dos hospitais estaduais passou a ser executada, prioritariamente, por meio das terceirizaçôes (PINTO, 2004).

Em 2003, com a atualização do Programa Estadual das Organizaçôes Sociais, pela Lei no 8.647/03, essas entidades foram incorporadas à gestão da Rede Hospitalar Própria (RHP) da Bahia e, ao longo de dez anos, substituindo as terceirizaçóes e ganhando novos espaços. A gestão hospitalar passou a ser orientada pela lógica privada, destacando-se a incorporação das OSS como importante evento no processo de publicização no estado.

Ressalta-se que há uma escassez na literatura nacional sobre o tema, o que não é congruente com a sua relevância. No tocante ao Estado da Bahia, a criação precoce da Lei das Organizaçóes Sociais, em relação a outros estados da Federação, e a incorporação progressiva das novas modalidades de gestão em um contexto neoliberal de gestáo, tornam-no especialmente apropriado ao estudo do processo de "publicização" da rede de serviços do Sistema Único de Saúde (SUS). Além disso, apesar de se constituir em processo global, as marcantes diferenças entre os sistemas de saúde nacionais e regionais exigem a realização de estudos empíricos delimitados e coerentes com suas especificidades estruturais, que permitam aprofundar o conhecimento acerca dos caminhos e formatos assumidos pela privatizaçáo do cuidado no SUS. Dessa forma, este artigo tem por objetivos: descrever o processo da "publicização" da gestão hospitalar, bem como analisar a incorporação das OSS no cenário da gestão dos hospitais estaduais da Bahia.

\section{Métodos}

Trata-se de estudo de caso, descritivo e analítico, sobre a publicização da gestáo hospitalar na Bahia, desenvolvido em dois momentos. ${ }^{1}$ No primeiro momento, foi realizada a caracterização da RHP da Secretaria de Saúde do Estado da Bahia (SESAB), a partir da análise de documentos como: atas das reuniôes do Conselho Estadual de Saúde (CES), do período de 2007 a 2014; edital de seleção para publicização do Hospital Professor Carvalho Luz (2012); relatório de auditoria operacional do Tribunal de Contas da Uniáo, relativo à publicização para OSS; Política Nacional de Atenção Hospitalar (PNAHOSP); e, por fim, uma lista atualizada, disponibilizada pela SESAB, dos hospitais que compunham a RHP sob 
GI, e suas respectivas instituiçôes gestoras. Além disso, algumas informaçôes foram obtidas em sites de domínio público (Cadastro Nacional de Estabelecimentos de Saúde - CNES e SESAB).

A extração de informaçóes importantes contidas nos documentos permitiu a construção de um quadro para descrição dos eventos concernentes ao processo de publicização hospitalar na Bahia, desde o governo de Paulo Souto, quando se deu início ao processo, até fins da gestão de Jaques Wagner (quadro 1).

Quadro 1. Descriçáo dos eventos concernentes ao processo de publicizaçáo hospitalar, no Estado da Bahia, com relaçáo às respectivas gestốes estaduais

\begin{tabular}{|l|l|l|}
\hline GESTÃO ESTADUAL & PERÍODO & $\begin{array}{l}\text { PROCESSO DE PUBLICIZAÇÃO } \\
\text { HOSPITALAR }\end{array}$ \\
\hline Paulo Souto & $1995-1998$ & $\begin{array}{l}\text { Criação das Organizaçóes Sociais; } \\
\text { Início das Terceirizaçóes. }\end{array}$ \\
\hline César Borges & $1999-2002$ & Ascensão das Terceirizaçóes. \\
\hline Paulo Souto & $2003-2006$ & $\begin{array}{l}\text { Atualização do Programa Estadual de } \\
\text { Organizaçóes Sociais; } \\
\text { Declínio das terceirizaçóes e consolidação das } \\
\text { OSS. }\end{array}$ \\
\hline Jaques Wagner & $2007-2014$ & $\begin{array}{l}\text { Criação das Fundaçóes Estatais; } \\
\text { Crescimento das OSS na gestão hospitalar; } \\
\text { Declínio das terceirizaçóes; } \\
\text { Retomada da Parceria Público-Privada. }\end{array}$ \\
\hline
\end{tabular}

Fonte: Elaborado pelas autoras.

No segundo momento, foi desenvolvido o estudo de caso com foco no retorno das OSS e sua consolidação no cenário hospitalar baiano. A caracterização da RHP da Sesab, desenvolvida no primeiro momento desta investigação, proporcionou a seleção de três hospitais sob GI, para serem lócus desta pesquisa, baseada em convergências identificadas nas características de cada unidade. Frente à dificuldade em obter a anuência dos hospitais para entrada em campo, o critério principal para a escolha foi a permissão para coleta de dados, que foi concedida por dois hospitais geridos por OSS (pela mesma entidade gestora) e um hospital gerido por terceirização. 
Os sujeitos do estudo foram os gestores ocupantes dos cargos da alta direção dos hospitais, de acordo com o organograma vigente no momento da coleta de dados, que concordaram em participar da pesquisa. Entendendo-se a importância do poder decisório dos gestores da SESAB, foi convidado a integrar o estudo, o Coordenador da Diretoria da Rede Própria sob Gestão Indireta (DIRPGI) da SESAB, responsável pelo acompanhamento dos contratos com OSS e com empresas terceirizadas. Ressalta-se a indisponibilidade e ausência de agenda do diretor da DIRPGI, da superintendente de atenção à saúde da SESAB e do secretário estadual de Saúde. A fim de assegurar o anonimato requerido, gestores, hospitais e respectivas entidades que os geriam no momento desta investigação foram nomeados com códigos (quadro 2).

Quadro 2. Apresentação dos códigos das instituiçóes lócus do estudo, dos seus respectivos modelos de gestấo e entidades gestoras e dos sujeitos do estudo.

\begin{tabular}{|l|l|l|l|}
\hline INSTITUIÇÃO & $\begin{array}{l}\text { MODELO DE } \\
\text { GESTÃO }\end{array}$ & $\begin{array}{l}\text { ENTIDADE } \\
\text { GESTORA }\end{array}$ & GESTORES (AS) \\
\hline H1 & OSS & EO & $\begin{array}{l}\text { Diretor-geral (DG1) } \\
\text { Diretor administrativo (DA1) }\end{array}$ \\
\hline H2 & OSS & EO & $\begin{array}{l}\text { Diretor-geral (DG2) } \\
\text { Diretor administrativo (DA2) }\end{array}$ \\
\hline H3 & Terceirização & ET & Diretor-geral (DG3) \\
\hline SESAB/DIRPGI & - & - & Coordenador (CGI) \\
\hline
\end{tabular}

Fonte: Elaborado pelas autoras.

Com o intuito de obter declaraçôes do secretário de Saúde, tanto da gestão em curso quanto das anteriores, buscaram-se entrevistas em jornais e revistas de saúde, acerca do referido tema, com publicaçóes no período de 1995 a 2014.

Cada gestor foi contatado previamente e informado sobre a pesquisa mediante esclarecimento verbal e assinatura do Termo de Consentimento Livre e Esclarecido, respeitando-se os princípios éticos e legais da Resolução 466/2012, do Conselho Nacional de Saúde. Como técnica para coleta de dados, utilizou-se, neste segundo momento, de entrevistas semiestruturadas, com o auxílio de recurso eletrônico para gravação de voz, feitas nos meses de dezembro de 2014 e janeiro de 2015. 
As entrevistas transcritas e os documentos obtidos foram analisados com o auxílio da técnica de Análise Crítica do Discurso, focalizada e guiada pelos objetivos da pesquisa, em acordo com o quadro de análise (quadro 3). Esse quadro incorpora categorias históricas, tomando como base os eventos descritos no quadro 1, e a noção de discurso frente a todo o processo histórico de incorporação das OSS ao cenário hospitalar baiano. A análise dos momentos históricos permitiu, portanto, a identificaçáo de elementos importantes para o objetivo deste estudo, que subsidiou a construção das categorias analítico-operacionais a partir de conceitos norteadores (quadro 4).

Quadro 3. Categorias históricas e analítico-operacionais relacionadas à incorporação das OSS ao cenário hospitalar baiano.

\begin{tabular}{|c|c|}
\hline CATEGORIAS HISTÓRICAS & CATEGORIAS OPERACIONAIS DE ANÁLISE \\
\hline Criação das Organizaçóes Sociais & $\begin{array}{l}\text { Discurso governamental } \\
\text { Aspectos jurídicos } \\
\text { Atuação do CES }\end{array}$ \\
\hline Ascensão das Terceirizaçóes & $\begin{array}{l}\text { Discurso governamental } \\
\text { Aspectos jurídicos } \\
\text { Atuação do CES } \\
\text { Processo contratual com as entidades gestoras }\end{array}$ \\
\hline $\begin{array}{l}\text { Consolidação das OSS e declínio } \\
\text { das terceirizações }\end{array}$ & $\begin{array}{l}\text { Discurso governamental } \\
\text { Aspectos jurídicos } \\
\text { Atuação do CES } \\
\text { Atuação do CONGEOS } \\
\text { Processo contratual com as entidades gestoras } \\
\text { Processo de transição de modelo jurídico: das } \\
\text { terceirizações para OSS }\end{array}$ \\
\hline
\end{tabular}

Fonte: Elaborado pelas autoras. 
Quadro 4. Conceitos norteadores das categorias operacionais de análise

\begin{tabular}{|c|c|}
\hline $\begin{array}{l}\text { CATEGORIAS } \\
\text { OPERACIONAIS DE ANÁLISE }\end{array}$ & CONCEITOS NORTEADORES \\
\hline Discurso Governamental & $\begin{array}{l}\text { Discurso dos gestores do governo estadual, bem } \\
\text { como da Secretaria Estadual de Saúde, durante todo } \\
\text { o processo de publicizaçấo da gestão hospitalar, na } \\
\text { Bahia. O discurso é aqui entendido como texto e } \\
\text { prática discursiva referentes a instituiçôes que situam } \\
\text { e limitam, historicamente, o evento discursivo } \\
\text { (FAIRCLOUGH, 1995). Aos diferentes grupos } \\
\text { sociais, em suas relaçóes políticas e ideológicas, } \\
\text { correspondem diferentes discursos políticos, tais como } \\
\text { o discurso liberal, conservador ou social-democrata, } \\
\text { dentre outros. }\end{array}$ \\
\hline Aspectos Jurídicos & $\begin{array}{l}\text { Aspectos legais, regulatórios e constitucionais frente } \\
\text { ao processo de publicização da gestáo hospitalar. }\end{array}$ \\
\hline $\begin{array}{l}\text { Atuação do Conselho Estadual de } \\
\text { Saúde (CES) }\end{array}$ & $\begin{array}{l}\text { Deliberação, fiscalização e propostas do CES diante } \\
\text { da proliferação de modalidades alternativas à gestão } \\
\text { estatal direta, nos hospitais. }\end{array}$ \\
\hline $\begin{array}{l}\text { Atuação do Conselho de Gestão } \\
\text { das Organizaçôes Sociais } \\
\text { (CONGEOS) }\end{array}$ & $\begin{array}{l}\text { Atuação e finalidade do CONGEOS no processo de } \\
\text { publicização da gestão hospitalar sob o modelo de } \\
\text { OSS. }\end{array}$ \\
\hline $\begin{array}{l}\text { Processo Contratual com as } \\
\text { Entidades Gestoras }\end{array}$ & $\begin{array}{l}\text { Processo de contrato do Estado com as entidades } \\
\text { gestoras (OSS), desde a decisão de um hospital ser ou } \\
\text { náo gerido por OSS até a sua construçáo e submissáo } \\
\text { ao CES e CONGEOS. }\end{array}$ \\
\hline $\begin{array}{l}\text { Processo de transição de modelo } \\
\text { jurídico: das Terceirizações para } \\
\text { OSS }\end{array}$ & $\begin{array}{l}\text { Processo de declínio das terceirizaçóes sob os aspectos } \\
\text { legais e políticos, a incorporaçáo das OSS ao cenário } \\
\text { hospitalar baiano e sua consolidaçáo como modelo de } \\
\text { gestão indireta predominante. }\end{array}$ \\
\hline
\end{tabular}

Fonte: Elaborado pelas autoras. 


\section{Resultados e Discussão}

O resgate histórico do processo de publicização da rede hospitalar pública forma uma linha do tempo que tem como base as iniciativas que permeiam a Reforma de Estado (RE) no Brasil, levada a cabo nos anos 1990. As mudanças políticas que frearam, momentaneamente, esse processo, o fizeram reviver e tomar corpo, de forma discreta e incremental, ainda nos primeiros anos do governo "esquerdista" do presidente Luiz Inácio da Silva, sendo reverberado no Governo do Estado da Bahia com a reemergência das OSS, no seu cenário hospitalar.

\section{O processo da criação das Organizaçóes Sociais de Saúde na Bahia}

A proposta de criação de um novo modelo organizacional (as Organizaçóes Sociais), no Estado da Bahia, foi introduzida no governo de Paulo Souto, em 1995. Indicado para suceder Antônio Carlos Magalhães (ACM), Paulo Souto assumiu o Governo da Bahia alicerçado pelas ideias reformistas, já introduzidas no cenário baiano pelo seu antecessor, e reafirmou as características da trajetória política "carlista" (BAHIA, 2002; DANTAS NETO, 2003).

A agenda de RE foi imprimida no cenário nacional pelo governo de FHC, com a implantação do PDRAE, e seguida à risca pelo Governo da Bahia. A proposta era de um novo gerencialismo público, que balizaria a busca por novas alternativas de gestão, para garantir eficiência e modernização da "máquina administrativa" (PINTO, 2004; BAHIA, 2002). No setor da saúde, especificamente, buscavam-se modelos modernos e eficientes de gestão organizacional que fortalecessem parcerias com o setor privado, transferindo-lhe a responsabilidade na execução de serviços e restringindo a produção estatal a serviços "básicos" (BAHIA, 2004a; PINTO, 2004; COSTA, 1998).

Em consonância com as propostas elaboradas pelo PDRAE, e em meio à grave crise hospitalar que se instalara no Estado da Bahia, o processo de modernização se deu a partir da criação das OSS para responsabilização pela gestão dos hospitais da rede estadual, o que desencadeou uma série de conflitos (PINTO, 2004).

Em 1996, este foi o tema central do CES: discutiam-se as alternativas para o problema da gestáo dos hospitais estaduais diante de um certo "descrédito" da equipe do governo, na manutençáo da gestão estatal direta dessas unidades. Em meio a posiçôes divergentes acerca do modelo de gestão ideal, "bateu-se o martelo" 
na proposta do governo que daria uma resposta rápida e coerente com o programa de modernização (BAHIA, 2002).

A posteriori, em janeiro de 1997, foi promulgada a Lei Estadual no 7.027, que instituiu o PIOS, na Bahia, tendo por objetivo "fomentar a absorção de atividades que, por força de previsão constitucional, já vinham sendo exercidas, também, pelo setor privado, pelas Organizaçóes Sociais" (BAHIA, 1997a). Essa lei foi regulamentada em junho de 1997, pelo decreto no 6.480 e, em novembro, pelos decretos no 7.007 e 7.008 (BAHIA, 1997b; 1997c; 1997d). Mas, no Congresso Nacional, a Medida provisória (MP) no 1.591/97 também causou amplos debates, sendo transformada na Lei no 9.637, em 1998 (BRASIL, 1997; 1998). Esta última, além de dispor sobre a qualificação das Organizaçôes Sociais, instituiu o Programa Nacional de Publicização e extinguiu órgãos federais, que tiveram suas funções absorvidas pelas novas entidades.

Como pode ser percebido, a Lei das Organizações Sociais, na Bahia, foi instituída, até mesmo, antes da Lei Federal, destacando o protagonismo do estado na criação e posterior incorporação dessas entidades. $\mathrm{O}$ modelo alternativo de gestão adotado pela Bahia diferenciava-se da inciativa dos outros estados, à medida que guardava características mais consoantes à MP 1.591/97, onde não se objetivava, apenas, a terceirização da saúde, mas uma parceria com a iniciativa privada (nesse caso, as OSS, sem fins lucrativos) com uma maior amplitude (GONÇALVES, 1998). Porém, a promulgação das leis estadual e federal não foi suficiente para que as OSS atuassem, definitivamente. A discussão e movimentação política, no CES, nas universidades, sindicatos e em outros setores da sociedade, apontavam para fragilidades e irregularidades jurídicas. Além do que, havia insatisfação em outros organismos de controle social do SUS e preocupação com o rumo do processo, em vários setores, inclusive dentro da própria SESAB (PINTO, 2004).

Debatiam-se a inconstitucionalidade e ilegalidade das publicizaçóes, visto que as instituiçôes privadas, com ou sem fins lucrativos, deveriam participar do SUS de forma complementar (BRASIL, 1988). Porém, na prática, a intenção do Estado seria "entregar" suas unidades hospitalares para a iniciativa privada, que passaria a dispor das mesmas, como se suas fossem, recebendo, em contrapartida, recursos públicos, gerindo-as como particulares (GONÇALVES, 1998).

Ainda em 1998, um artigo sobre a qualificação das OSS, como um ato do poder público, criticou a subjetividade presente no texto da lei que delegava para o órgão 
executivo a decisão sobre a conveniência e oportunidade da entidade a ser qualificada, sem estabelecer critérios objetivos para esta qualificação, o que os autores chamaram de "descompasso entre o interesse que deveria ser juridicamente protegido pela Lei e a sua redação final” (BAHIA; CARVALHO, 1998).

Nesse contexto, vários movimentos foram desencadeados. Ressalta-se uma ação civil pública contra o Estado, pelo Ministério Público, durante o processo de tentativa da publicização do Hospital Geral Roberto Santos, em Salvador: o próprio diretor do hospital era quem dirigia a OSS, candidata à seleção pública, o que beneficiava, diretamente, pessoas vinculadas à administração pública (PINTO, 2004). Assim, mudou-se o rumo da GI na Bahia. Como os holofotes estavam voltados para o receio, as ilegalidades e a inconstitucionalidade das OSS, a partir de 1996 a terceirização passou a ser a principal modalidade de gestão dos hospitais públicos estaduais.

\section{A ascensão da terceirização na gestão dos hospitais públicos estaduais}

O debate em torno do modelo de gestão encampado pela OSS se deu no seio da PDRAE, como foi dito, e da reforma administrativa levada a cabo pelo governo estadual, a partir de 1998. Naquele momento, a contratação de serviços era preferencial para grandes e tradicionais instituiçôes filantrópicas do estado, enquanto as relaçôes com as entidades de representação civil se davam de maneira formal e pouco participativa. O CES funcionava, efetivamente, como órgão interno, sem qualquer autonomia, pois sua agenda era determinada pelo presidente do Conselho, que era o próprio secretário de Saúde (COELHO, 2001).

Desse modo, em meio aos embates políticos e jurídicos em torno do modelo alternativo a ser adotado pelo estado, na sua desresponsabilização pela prestação direta dos serviços de saúde, a SESAB optou por investir, principalmente, na terceirização da gestão hospitalar (BAHIA, 2002). A terceirização é bastante semelhante ao modelo das OSS, porém, a gestão é transferida para uma empresa privada, com fins lucrativos (MACHADO, 2001).

De acordo com a visão da SESAB, esta opção surgiu pela concepção de que o sistema de serviços públicos não poderia dar conta das demandas que se impunham ao sistema de saúde. Considerava-se que "esse era o caminho para a busca por maior flexibilidade e maior eficiência na prestação dos serviços de saúde no âmbito hospitalar" (BAHIA, 2002, p. 103). Além disso, a estabilidade dos funcionários públicos, a má remuneração, a falta de incentivo, a falta de conforto no 
trabalho, dentre outros, constituíam os principais motivos registrados pelo governo (KEINERT et al., 2006). De fato, no que se refere às condiçôes e relaçóes de trabalho, os hospitais públicos sob gestão direta foram mais mal avaliados por seus funcionários, em relaçâo aos outros modelos de gestão, segundo estudo realizado no Mato Grosso (SOUZA; SCATENA, 2014).

Numa entrevista concedida ao jornal Folha de S.Paulo, em 2000, o ex-secretário de Saúde José Maria de Magalhães Netto justificou o novo rumo da gestão hospitalar, na Bahia, utilizando a exaustão da gestão estatal. Para ele, a terceirização permitiria uma maior flexibilização para contrato e demissão de funcionários. Por sua vez, o custo seria menor e a eficiência, bem maior (MAGALHÁES NETTO, 2000).

As terceirizaçóes, na Bahia, eram alicerçadas pela Lei 8.666/93, que estabelece normas gerais sobre licitações e contratos administrativos pertinentes a serviços, no âmbito dos poderes concernentes aos quatro entes: União, Estados, Distrito Federal e Municípios (BRASIL, 1993). Porém, de acordo com o Relatório de Auditoria Operacional do TCU (2012), o contrato administrativo deveria ser utilizado para a aquisiçâo de serviços de saúde, não para a terceirização da gestão de unidades de saúde próprias (BRASIL, 2012). Dessa maneira, as terceirizaçôes foram se "apossando" da gestão indireta hospitalar, sem uma legislação que autorizasse, de fato, esse tipo de contrato.

Como precursor desse processo, destaca-se o hospital de Ibotirama, localizado no oeste do estado, palco para experimento da GI na Bahia, em 1996. O município sediava um hospital, com 50 leitos, construído em 1993, porém, a unidade não funcionava por falta de funcionários (KEINERT et al., 2006). Diante disso, optou-se pela tentativa da publicização da gestão do hospital para uma OSS. Não obstante, frente aos entraves políticos e judiciais e dificuldades de operacionalização dessa modalidade, a alternativa foi abrir um edital de concorrência pública para terceirização (BAHIA, 2002; KEINERT et al., 2006).

Ainda em 1996, foi firmado o primeiro contrato formal para gestão hospitalar terceirizada, em Salvador. Ao contrário do que se observou no processo de criação das OSS, não há registros nas atas das reunióes do CES, da época, no que diz respeito às posiçôes contrárias à terceirização da gestão dos hospitais, apenas receio da parte dos sindicatos dos profissionais de saúde e de outras categorias, por perdas consequentes de postos de trabalho para o funcionário público (BAHIA, 2002). Esse dado é coerente com o modo de operação dos entes privados lucrativos internacionais que 
professam a transparência no discurso enquanto se imiscuem no aparato estatal sem criar resistências significativas por parte das representações sociais e governamentais (SVALLFORS; TYLLSTRÖM, 2017).

Para o diretor-geral do H1, também ex-diretor do H3, a experiência pioneira da cidade de Ibotirama foi o ponto de partida para todas as outras posteriores, diante do "sucesso gerencial" em apenas seis meses. A empresa contratada, a ET, trazia para a área pública a experiência de gestão hospitalar de uma OSS, filantrópica, já estabelecida no cenário da gestão hospitalar e de uma importante empresa do ramo da construção civil.

Desse modo, em 2001, havia 12 unidades hospitalares administradas pela iniciativa privada, sob terceirização, distribuídas em dez municípios do estado (quadro 5): seis estavam sob a gestão de uma única empresa, sob a justificativa da SESAB de que, além de possuir, na época, uma experiência acumulada em gestão hospitalar, essa empresa investia em novas formas de organização de trabalho, permitindo a operacionalização com custos otimizados (BAHIA, 2002). Porém, destaca-se que o processo para essa modalidade de publicização era feito por licitação, prevalecendo, portanto, a orientação do menor preço, o que coloca aquela justificativa em suspeição (BRASIL, 1993).

Quadro 5. Hospitais estaduais sob gestão indireta, as respectivas empresas gestoras e ano de início do contrato, no período de 1996 a 2001.

\begin{tabular}{|l|l|l|}
\hline $\begin{array}{l}\text { ANO INÍCIO } \\
\text { CONTRATO }\end{array}$ & EMPRESA GESTORA & HOSPITAL \\
\hline 1996 & $\begin{array}{l}\text { SM Assessoria Empresarial e Gestão } \\
\text { Hospitalar S/C }\end{array}$ & Eládio Lasserre \\
\hline 1997 & $\begin{array}{l}\text { SM Assessoria Empresarial e Gestão } \\
\text { Hospitalar S/C }\end{array}$ & Hospital Regional de Ibotirama \\
\hline 1997 & $\begin{array}{l}\text { SM Assessoria Empresarial e Gestão } \\
\text { Hospitalar S/C }\end{array}$ & $\begin{array}{l}\text { Hospital Professor Carvalho } \\
\text { Luz }\end{array}$ \\
\hline 1998 & Castro e Lopes Ltda. & Hospital Geral de Guanambi \\
\hline 1998 & $\begin{array}{l}\text { SM Assessoria Empresarial e Gestão } \\
\text { Hospitalar S/C }\end{array}$ & Hospital de Paulo Afonso \\
\hline 1998 & Empresa Médica de Paramirim Ltda. & Hospital de Paramirim \\
\hline
\end{tabular}




\begin{tabular}{|c|c|c|}
\hline 1999 & $\begin{array}{l}\text { SM Assessoria Empresarial e Gestão } \\
\text { Hospitalar S/C }\end{array}$ & $\begin{array}{l}\text { Hospital de Porto Seguro - } \\
\text { Luiz Eduardo Magalhães }\end{array}$ \\
\hline 1999 & Castro e Lopes Ltda. & $\begin{array}{l}\text { Hospital Eurídice Santana - } \\
\text { Santa Rita de Cássia }\end{array}$ \\
\hline 2000 & Empresa Médica de Paramirim Ltda. & Hospital Castro Alves \\
\hline 2000 & Castro e Lopes Ltda. & $\begin{array}{l}8^{\circ} \text { Centro de Saúde - Unidade } \\
\text { de Emergência de Sáo Caetano }\end{array}$ \\
\hline 2000 & $\begin{array}{l}\text { SM Assessoria Empresarial e Gestão } \\
\text { Hospitalar S/C }\end{array}$ & Hospital Geral de Itaparica \\
\hline 2001 & Castro e Lopes Ltda. & $\begin{array}{l}\text { Hospital Luiz Eduardo } \\
\text { Magalhães Mairi }\end{array}$ \\
\hline
\end{tabular}

Fonte: Elaborado pelas autoras, a partir de informações extraídas de Bahia (2002) e Keinert et al. (2006).

O governo da Bahia expôs um estudo sobre a redução de custos hospitalares em unidades terceirizadas que ainda teriam sido avaliadas como excelentes, tomando-se como indicador a satisfação dos usuários desses hospitais. Ressalta-se a obtenção do prêmio ISO 9002 pelo H1, em 2000. Elogios não foram poupados ao governo frente aos dados divulgados e aos estudos comparativos entre a eficiência de hospitais sob gestáo direta (GD) e indireta, nos governos de Paulo Souto e César Borges. Porém, o "sucesso" das terceirizaçóes, incorporadas ao longo de um decênio (1996 a 2006), ainda era questionado e discutido em diversos setores da sociedade, principalmente pela oposição política (BAHIA, 2002).

Percebiam-se, ao longo da reforma gerencial, especificamente na Bahia, argumentos contrários e favoráveis às OSS influenciados por visóes ideológicas dos grupos políticos em disputa, contra e a favor do modelo (BRASIL, 2012). Esses argumentos respaldavam tanto os discursos do sucesso da implantação das OSS quanto os que relativizam o sucesso do empreendimento, levantando seus verdadeiros custos ao Tesouro público.

Em 2003, com a entrada do Partido dos Trabalhadores (PT) na condução do governo central, as OSS reemergiram a partir da Lei Estadual no 8.647/03, que atualizou o Programa Estadual de Organizaçóes Sociais, e do Decreto no 8.890/04, dando-lhe nova regulamentação (BAHIA, 2003; 2004b). As terceirizações, a partir de entáo, foram perdendo espaço para as OSS, sendo estabelecido, em 2005, o primeiro contrato na Bahia. 


\section{Consolidação das OSS no cenário hospitalar baiano: "É como se fosse o Estado"}

[...] a nossa tendência, nesses últimos oito anos, é a gente diminuir os contratos terceirizados, e partir pra os contratos com OSS. O que se pretende é ganhar eficiência de gestão. [...] O Estado precisa experimentar inúmeras formas de gestão e nisso o Estado da Bahia é interessante, porque ele tem feito! Tem se arriscado!(CGI).

Em 2007, a Bahia experimentou a "oposição" no poder, após 16 anos de uma trajetória política carlista. Jaques Wagner assumiu o governo do estado, permanecendo por oito anos. Nessa gestão, o secretário estadual de Saúde foi o médico especialista em saúde pública Jorge Solla, que disseminou, durante os primeiros anos da sua gestão, discursos contrários à política reformista do governo anterior. Em uma entrevista concedida à revista Luta Médica, em 2007, Solla criticou a política das terceirizaçóes do governo de Paulo Souto, as quais eram implementadas "com critérios nebulosos, sem transparência e controle social”, e defendeu a criação de "fundaçôes estatais" para aperfeiçoar a gestão das unidades hospitalares, no setor público (SOLLA, 2007, p.6).

Após nove meses de governo Wagner, a situação encontrada na gestão da saúde, na Bahia, foi apresentada na 134a Reuniáo Ordinária do CES: piores indicadores de saúde da Regiâo Nordeste; terceirização de grande parte da rede pública hospitalar estadual; vários contratos apresentando irregularidades; fragilidade dos mecanismos de gestão (BAHIA, 2007a).

Nesse sentido, era preciso colocar em prática mecanismos inovadores de gestão, a que Solla se referira, sem repetir "os critérios nebulosos" da gestão passada. Isso foi evidenciado em um discurso do ex-secretário, no início da sua gestão, em que ressaltou a manutenção ou renovação dos contratos de gestão com OSS, que estivessem apresentando boa prestação de serviços e adequação financeira, como ocorreu com o Hospital Santa Thereza, em Ribeira do Pombal. Nos casos em que o diagnóstico da gestão hospitalar evidenciasse prejuízo para a atenção à população e inadequada relação custo/benefício, os contratos seriam rescindidos ou não renovados. Ele explanou, ainda, o absurdo de se cobrar dos hospitais sob GD eficiência e resultados positivos, com baixa alocação de recursos financeiros, já que o financiamento baseavase em parâmetros diferenciados, com maior volume quando a gestão era terceirizada, denunciando isso como a "tônica do governo passado" (SOLLA, 2007). 
Em 2008, o cenário da gestão hospitalar estadual estava bem diferente de quatro anos atrás: 13 unidades sob GI e 27 unidades sob GD. Ressalta-se que 80\% dos hospitais de grande porte estavam sob a GD do Estado (BAHIA, 2009). Em 2009, a RHP da SESAB contava com 11 hospitais sob GI, sendo quatro por terceirização e sete por OSS (quadro 6).

Quadro 6. Relação dos hospitais que compunham a RHP da SESAB sob gestão indireta, seus modelos jurídicos de gestão e as respectivas instituiçóes gestoras, 2009

\begin{tabular}{|l|l|l|}
\hline UNIDADE & $\begin{array}{l}\text { MODELO DE } \\
\text { GESTÃO }\end{array}$ & INSTITUIÇÃO GESTORA \\
\hline Hospital Eládio Lasserre & Indireta - Terceirização & SM (Em ampliação) \\
\hline Hospital Carvalho Luz & Indireta - Terceirização & SM \\
\hline Emergência São Caetano & Indireta - Terceirização & DMX \\
\hline Hospital de Itaparica & Indireta - Terceirização & SM \\
\hline Hospital do Oeste - Barreiras & Indireta - OSS & OSID \\
\hline Hospital Santa Rita de Cassia & Indireta - OSS & OSID \\
\hline Hospital Castro Alves & Indireta - OSS & APMI \\
\hline Maternidade de Referência & Indireta - OSS & Santa Casa de Misericórdia \\
\hline Hospital de Porto Seguro & Indireta - OSS & $\begin{array}{l}\text { Monte Tabor (Em seleção } \\
\text { para nova OSS) }\end{array}$ \\
\hline Hospital de Alagoinhas & Indireta - OSS & Monte Tabor \\
\hline Hospital de Ribeira do Pombal & Indireta - OSS & Fundação José Silveira \\
\hline
\end{tabular}

Fonte: Elaborado pelas autoras, a partir de dados extraídos de Bahia (2009).

A tendência das OSS estava confirmando-se. De acordo com CGI, a publicização da gestão para OSS seria mais vantajosa para o estado, visto que a terceirização visaria ao lucro, o que iria requerer o pagamento de uma taxa administrativa. Para o gestor, o acordo estabelecido entre uma OSS e o estado aproximava-se mais de um convênio do que de um contrato, de fato:

[...] a gente tem visto que para o Estado isso é mais vantajoso, porque o terceirizado, pela própria natureza do contrato, ele quer lucro! Por isso, a própria lei autoriza que ele cobre uma taxa de administraçáo que varia até $20 \%$ do valor do contrato. Os contratos com OSS, na verdade, eles têm uma natureza de convênio. Então é como se o próprio Estado estivesse na gestáo desses hospitais. E as OSS não podem, não devem, ter lucro nem prejuízo (CGI, grifo nosso). 
Entretanto, apesar de o discurso vigente ser de que a OSS era "como se fosse o Estado", havia, na prática, uma "transferência da gestão de serviços e atividades não exclusivas do Estado para o setor público não estatal”, como o próprio conceito de publicização explicita (BAHIA, 2004a), sob o estabelecimento de um contrato de gestâo. A utilização do termo "publicização" para denominar a entrega da gestão pública a um ente não estatal parece muito próxima do que foi apontado na literatura crítica como reinvenção da democracia e apropriação da noção de interesse público mediante um claro jogo discursivo de inversão de sentido (KAMAT, 2004).

Já os diretores gerais do $\mathrm{H} 1$ e $\mathrm{H} 2$ trataram da diminuição dos contratos terceirizados por uma decisão do Ministério Público, frente à ilegalidade das terceirizações da gestão hospitalar, ratificando a tendência da gestão hospitalar na Bahia, para OSS e, também, PPP.

No âmbito jurídico, discutia-se, ainda, se o processo de publicização, tanto por OSS, quanto por terceirização, feria os princípios constitucionais ou não. O Art. 197 da Constituição Federal prevê a participação da iniciativa privada de forma complementar na execuçấo de ações, quando a capacidade instalada do Estado (prédios, equipamentos, corpo médico, instalaçôes etc.) for insuficiente para atender à demanda (GONÇALVES, 1998). Para essa participação, dá-se preferência, pelas regras vigentes, às entidades filantrópicas ou sem fins lucrativos (BRASIL, 1988). Mas a participação da iniciativa privada foi prevista para o "atendimento" à população, não para a gestão de instituições públicas.

No caso específico das terceirizaçôes, determinou-se, através da Ação Direta de Inconstitucionalidade no $1.923 / \mathrm{DF}$, a ilegalidade dos contratos de duas empresas, dentre elas a ET, contratada para gerir quatro hospitais, inclusive o $\mathrm{H} 1$ e o H3, além de outras ilegalidades referentes à publicização hospitalar.

Unia-se, então, o que era vantajoso para o Estado à tentativa de "amenizar" a inconstitucionalidade. Em 2009, mais um hospital foi entregue à gestão particular. $\mathrm{O} \mathrm{H} 2$, que levou 18 anos para ter a sua construção concluída, foi inaugurado em dezembro de 2009, já sob a gestão de uma OSS, a EO. Segundo CGI, em consonância com a Lei Estadual no $8647 / 03$, para que ocorresse este tipo de publicização, deverse-iam seguir determinados trâmites.

A decisão de um hospital ser ou não gerido por uma OSS era feita, normalmente, pelo gabinete do secretário de Saúde, que as definia junto com as diretorias. Uma vez definido que haveria a publicização, era construído um projeto, que nada mais era 
do que o estudo da unidade e, se a unidade estivesse acabado de ser construída (caso do H2), o projeto de publicização era feito com base nos estudos epidemiológicos e comparativos com outras unidades do mesmo perfil. Esse projeto deveria conter propostas, metas, riscos e uma estimativa do recurso necessário para operar aquela unidade. Uma vez construído, deveria ser submetido ao Conselho de Gestão das Organizaçôes Sociais (CONGEOS), composto por secretários de todas as secretarias que têm contratos com Organizaçóes Sociais e, também, representantes da sociedade civil. Por uma determinação do TCU, deveria ser submetido, ainda, à apreciação do CES (BAHIA, 2003; BRASIL, 2012).

De acordo com CGI, o CES sempre foi favorável às publicizaçôes, ao longo de todo o processo. Entretanto, na 135ª Reunião Ordinária do CES, em 2007, uma conselheira, que no momento estava como suplente do CONGEOS denunciou a falta de conhecimento de muitos conselheiros do CES sobre o CONGEOS e as deliberaçôes que não ocorreram no CES:

[...] Está aqui nos relatórios que todos os hospitais que nos governos anteriores começaram a investir nessa forma de gestão [Referente à OSS], mas o governo atual não conseguiu ainda barrar como gostaríamos. [...] tem aqui a renovaçáo de contratos que náo passou por este Conselho, uma minuta de renovação de contrato do Monte Tabor com relação ao Dantas Bião que a perspectiva era de ser municipalizado e esse relatório tem uma minuta e não tem nosso conhecimento. Se o município não aceitou e não houve discussão, então como é que aqui já tem uma minuta de renovação de contrato? (BAHIA, 2007b, p. 15).

No caso do H2, também não havia registros nas atas do CES sobre a deliberação da sua publicização. Esse assunto foi abordado por Solla, na 154ª Reunião Ordinária, em 2009, ao responder a uma conselheira sobre a existência do CONGEOS, ainda questionada, e sobre a possibilidade de o $\mathrm{H} 2$ ser gerido por uma fundação estatal:

[...] Infelizmente, vamos ter que abrir o $\mathrm{H} 2$ fazendo contrato de OSS, porque o nosso projeto original era que o $\mathrm{H} 2$ viesse a ser o primeiro hospital público na Bahia com fundação estatal [...]. No marco atual, hoje nem a Secretaria Estadual, nem a Universidade Federal do Recôncavo tem como assumir esse hospital na GD. A única alternativa para que coloquemos esse hospital em operação neste momento é fazer uma seleção de OSS. Realmente, não tivemos alternativa, infelizmente, [...] mas tenho certeza que iremos superar as adversidades (BAHIA, 2009, p. 16).

A priori, a criação das fundações estatais para a administração de hospitais públicos, na Bahia, era política prioritária no governo de Jaques Wagner, na "desprivatização" da saúde herdada do governo anterior, sob o discurso de maior autonomia, flexibilidade e participação do controle social. Para Solla, as fundaçóes 
teriam uma capacidade gerencial que a GD não tinha e que, em parte, as OSS possuíam, apesar de funcionarem mal. Esta foi a justificativa do secretário para a criação das fundaçóes estatais, desconsiderando as OSS como modelo alternativo adequado para a rede hospitalar (SOLLA, 2009).

Estranhamente, em dezembro de 2009, na seleção pública para publicização do $\mathrm{H} 2$, a EO foi qualificada como OSS e assumiu a gestáo do hospital. O valor investido neste processo foi de $\mathrm{R} \$ 5.355 .068,40$, completamente díspar ao que se investia na aquisição de equipamentos para hospitais sob GD (BAHIA, 2011).

Em 2011, foi feito um comparativo, no CES, com relação ao investimento do governo, nos hospitais que seriam publicizados. Apesar de Solla ter denunciado na $11^{\text {a }}$ Conferência Nacional de Saúde, no ano de 2000, que $80 \%$ dos recursos do SUS eram transferidos para o setor privado, na sua gestão não estava muito diferente (BAHIA, 2011). Constatou-se que, no ano de 2011, foram aplicados R $\$$ 498,4 milhóes para administração das 18 unidades hospitalares e ambulatoriais sob GI. Nas 23 unidades sob GD, foram provisionados $\mathrm{R} \$ 184$ milhóes, sem contabilizar o pagamento da folha de pessoal (BAHIA, 2012). Como a folha de pessoal, segundo a Lei de Responsabilidade Fiscal, não deve ultrapassar 50\% do gasto com custeio, pode-se estimar o gasto com as unidades diretas em cerca de 370 milhóes, o que estaria bem abaixo do gasto com a GI. Sabe-se que a EO é do mesmo grupo da ET, empresa que iniciou a terceirização da gestão hospitalar na Bahia, predominando por alguns anos. Em 2012, dois dos hospitais que estavam sob a gestão da ET, o H1 e um outro hospital do interior da Bahia passaram a ser geridos pela EO. Também não se tem registros nas atas do CES sobre o processo de publicização desses hospitais para OSS, nem da "migração" da gestão desses hospitais da ET (terceirização) para EO (OSS).

Quando questionados a respeito da homogeneidade da EO e ET, os gestores afirmaram que apenas a EO surgiu "dos saberes" da ET. Porém, em diversos momentos das entrevistas, utilizaram a primeira pessoa do plural para se referirem às empresas:

Nós somos os primeiros em gestão hospitalar, na Bahia. [...] A EO surgiu pela vontade de algumas pessoas que são da ET, em ter um instituto. [...] Ora, a EO, tem os saberes que migraram e que foram absorvidos e aprimorados pela ET (DG1, grifo nosso).

Nós temos uma PPP com outra empresa, totalmente diferente desse contrato... A EO surgiu da ET. A ideia era a continuidade disso (DG2, grifo nosso). 
Ainda em 1998, Santos denunciou esse processo como uma espécie de fraude à Constituição, à medida que o Programa de Publicização permitia que entidades preexistentes fossem travestidas em OSS, por meio de uma ação "entre amigos". Além disso, constatou-se também que o quadro de diretores dos hospitais, que antes era gerido pela ET e agora pela EO, era o mesmo, existindo, apenas em alguns casos, a permuta do diretor de um hospital para outro.

Até fevereiro de 2015, o grupo ET/EO administrava cinco hospitais estaduais, na Bahia, dos 18 que compunham a rede própria sob GI. Desses, 15 eram hospitais gerais, três desses, de grande porte (quadro 7). De um modo geral, a RHP da SESAB era composta por 41 hospitais: 23 estavam sob a GD do estado, 15 geridos por OSS, dois por terceirização e um por PPP (quadro 8). 


\begin{tabular}{|c|c|c|c|c|c|c|c|c|c|c|c|c|c|}
\hline 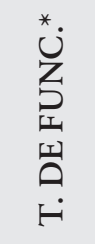 & 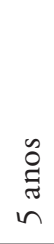 & 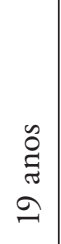 & 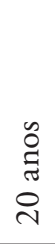 & 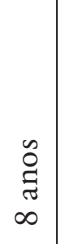 & 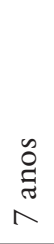 & $\begin{array}{l}\tilde{o} \\
\tilde{\sigma} \\
0\end{array}$ & 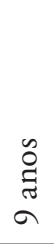 & $\begin{array}{l}\tilde{O} \\
\stackrel{\Xi}{\Xi} \\
=\end{array}$ & $\begin{array}{l}\stackrel{0}{0} \\
\tilde{\sigma} \\
a\end{array}$ & 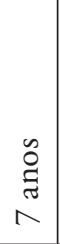 & $\begin{array}{l}0 \\
\Xi \\
\beth \\
=\end{array}$ & 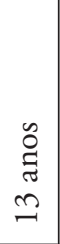 & 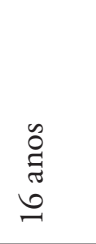 \\
\hline 罗 & ت্ّँ & $\begin{array}{l}\overrightarrow{\widetilde{U}} \\
\vec{U}\end{array}$ & ت্ّँ & 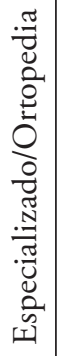 & $\begin{array}{l}\bar{\pi} \\
\stackrel{\Xi}{0}\end{array}$ & 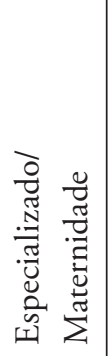 & $\begin{array}{l}\bar{\pi} \\
\stackrel{\Xi}{0}\end{array}$ & 苛 & 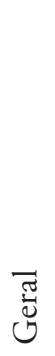 & $\begin{array}{l}\vec{\pi} \\
\stackrel{\vec{U}}{U}\end{array}$ & $\begin{array}{l}\vec{\pi} \\
\stackrel{0}{U}\end{array}$ & 荧 & 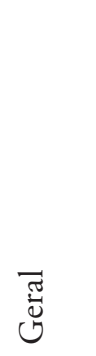 \\
\hline 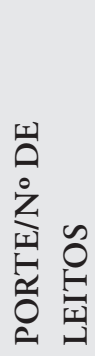 & 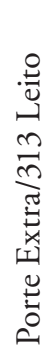 & 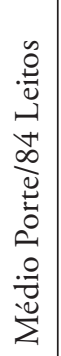 & 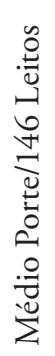 & 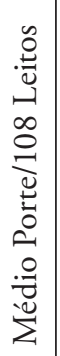 & 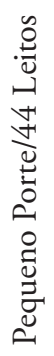 & 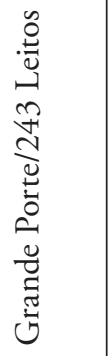 & 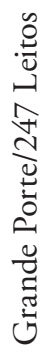 & 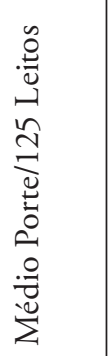 & 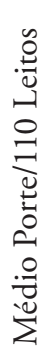 & 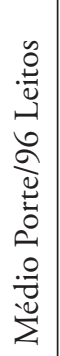 & 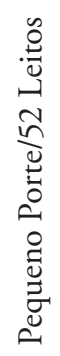 & 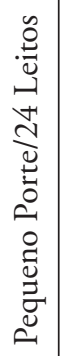 & 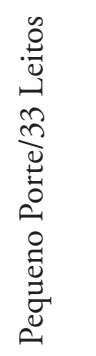 \\
\hline 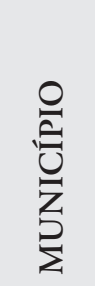 & 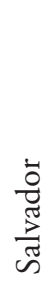 & $\begin{array}{l}\frac{\ddot{0}}{\tilde{D}} \\
\frac{\vec{D}}{\tilde{D}}\end{array}$ & $\frac{\overrightarrow{0}}{\frac{\tilde{\sigma}}{\tilde{J}}}$ & $\begin{array}{c}\frac{\dot{0}}{\tilde{\sigma}} \\
\frac{\tilde{J}}{\tilde{D}} \\
\tilde{D}\end{array}$ & 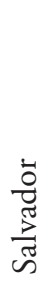 & $\begin{array}{l}\frac{\overrightarrow{0}}{\tilde{\sigma}} \\
\frac{\vec{z}}{\tilde{D}}\end{array}$ & 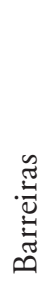 & 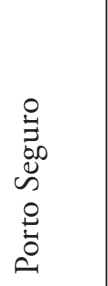 & 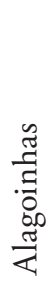 & 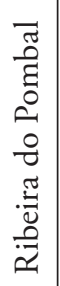 & 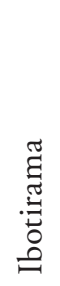 & 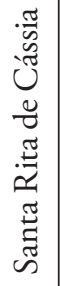 & $\stackrel{\Xi}{\sum_{\pi}^{*}}$ \\
\hline 穵 & 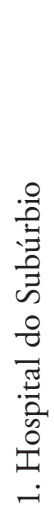 & 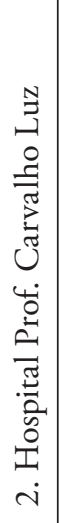 & 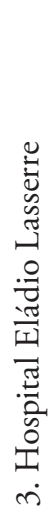 & 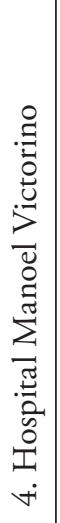 & 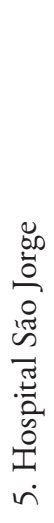 & 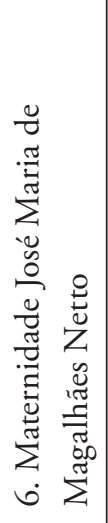 & 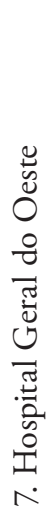 & 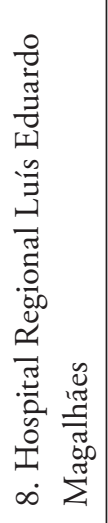 & 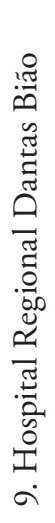 & 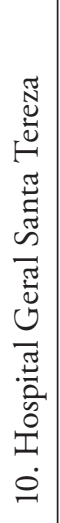 & 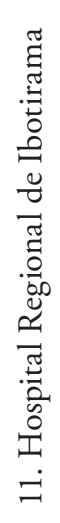 & 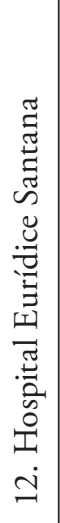 & 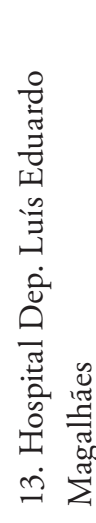 \\
\hline
\end{tabular}


| Página 22 de 32

\begin{tabular}{|c|c|c|c|c|c|c|}
\hline 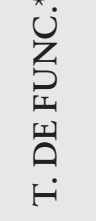 & $\begin{array}{l}\mathscr{0} \\
\stackrel{\Xi}{\sigma} \\
\end{array}$ & $\begin{array}{c}\stackrel{0}{0} \\
\stackrel{\Xi}{\sim} \\
\sim\end{array}$ & $\underset{\sim}{\stackrel{0}{0}}$ & 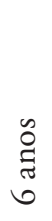 & 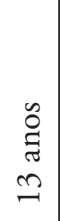 & 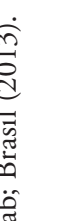 \\
\hline 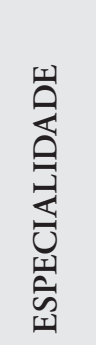 & $\begin{array}{l}\overrightarrow{\widetilde{J}} \\
\stackrel{\Xi}{U}\end{array}$ & $\begin{array}{l}\overrightarrow{\widetilde{J}} \\
\stackrel{U}{U}\end{array}$ & $\begin{array}{l}\bar{\Xi} \\
\stackrel{\Xi}{U}\end{array}$ & 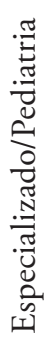 & $\begin{array}{l}\overline{\widetilde{J}} \\
\stackrel{U}{U}\end{array}$ & 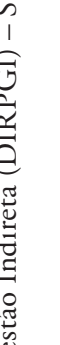 \\
\hline 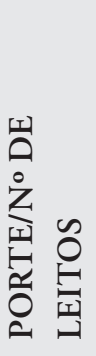 & 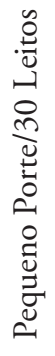 & 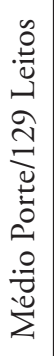 & 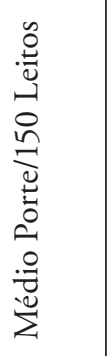 & 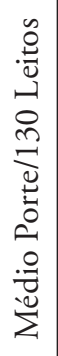 & 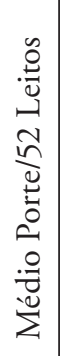 & 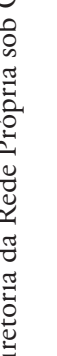 \\
\hline 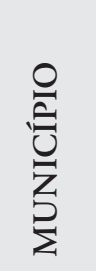 & 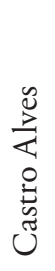 & $\begin{array}{l}\stackrel{0}{\stackrel{\Xi}{N}} \\
\stackrel{\widetilde{J}}{\Xi}\end{array}$ & 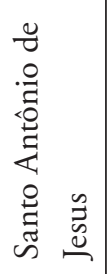 & 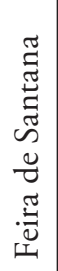 & 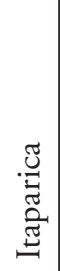 & 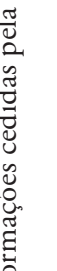 \\
\hline 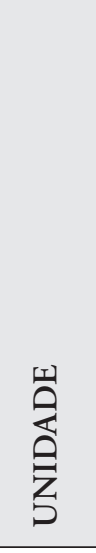 & 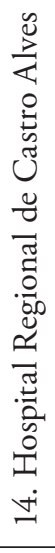 & 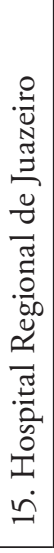 & 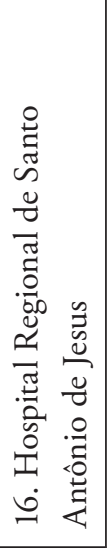 & 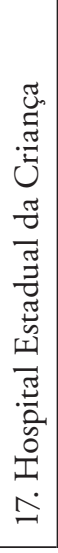 & 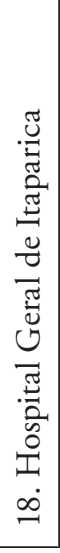 & 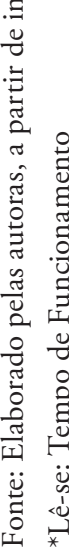 \\
\hline
\end{tabular}


Quadro 8. Relação dos hospitais que compunham a RHP da SESAB, seus modelos jurídicos de gestão e as respectivas instituiçóes gestoras, 2015.

\begin{tabular}{|c|c|c|}
\hline HOSPITAL & $\begin{array}{l}\text { MODELO DE } \\
\text { GESTÃO }\end{array}$ & $\begin{array}{l}\text { INSTITUIÇÃO } \\
\text { GESTORA }\end{array}$ \\
\hline & CAPITAL & \\
\hline Hospital Geral Roberto Santos & Direta & SESAB \\
\hline Hospital Geral do Estado & Direta & SESAB \\
\hline Hospital do Subúrbio & Indireta - PPP & Prodal Saúde \\
\hline Hospital Couto Maia & Direta & SESAB \\
\hline Hospital Prof. Carvalho Luz & Indireta - OSS & $\begin{array}{l}\text { Instituto Fernando } \\
\text { Filgueiras - IFF }\end{array}$ \\
\hline Hospital Eládio Lasserre & Indireta - Terceirização & $\begin{array}{l}\text { SM - Assessoria Empresarial } \\
\text { e Gestão Hospitalar Ltda. }\end{array}$ \\
\hline Hospital Manoel Victorino & Indireta - OSS & $\begin{array}{l}\text { Instituto Brasileiro de } \\
\text { Administraçáo Hospitalar - } \\
\text { IBDAH }\end{array}$ \\
\hline $\begin{array}{l}\text { Hospital Especializado Octávio } \\
\text { Mangabeira }\end{array}$ & Direta & SESAB \\
\hline $\begin{array}{l}\text { Hospital Psiquiátrico Juliano } \\
\text { Moreira }\end{array}$ & Direta & SESAB \\
\hline Hospital São Jorge & Indireta - OSS & $\begin{array}{l}\text { Obras Sociais Irmã Dulce - } \\
\text { OSID }\end{array}$ \\
\hline $\begin{array}{l}\text { Hospital Especializado Mário } \\
\text { Leal }\end{array}$ & Direta & SESAB \\
\hline $\begin{array}{l}\text { Hospital Geral João Batista } \\
\text { Caribé }\end{array}$ & Direta & SESAB \\
\hline $\begin{array}{l}\text { Hospital Geral Menandro de } \\
\text { Faria }\end{array}$ & Direta & SESAB \\
\hline Hospital Ernesto Simôes Filho & Direta & SESAB \\
\hline $\begin{array}{l}\text { Hospital Especializado Dom } \\
\text { Rodrigo de Menezes }\end{array}$ & Direta & SESAB \\
\hline
\end{tabular}




\begin{tabular}{|c|c|c|}
\hline HOSPITAL & $\begin{array}{l}\text { MODELO DE } \\
\text { GESTÃO }\end{array}$ & $\begin{array}{l}\text { INSTITUIÇÃO } \\
\text { GESTORA }\end{array}$ \\
\hline & INTERIOR & \\
\hline $\begin{array}{l}\text { Hospital Geral do Oeste - } \\
\text { Barreiras }\end{array}$ & Indireta - OSS & $\begin{array}{l}\text { Obras Sociais Irmã Dulce - } \\
\text { OSID }\end{array}$ \\
\hline $\begin{array}{l}\text { Hospital Geral Clériston } \\
\text { Andrade - Feira de Santana }\end{array}$ & Direta & SESAB \\
\hline $\begin{array}{l}\text { Hospital Luís Eduardo } \\
\text { Magalhães - Porto Seguro }\end{array}$ & Indireta - OSS & Monte Tabor \\
\hline $\begin{array}{l}\text { Hospital Regional Dantas Bião } \\
\text { - Alagoinhas }\end{array}$ & Indireta - OSS & Monte Tabor \\
\hline $\begin{array}{l}\text { Hospital Geral Sta Tereza - } \\
\text { Ribeira do Pombal }\end{array}$ & Indireta - OSS & Fundação José Silveira - FJS \\
\hline $\begin{array}{l}\text { Hospital Especializado Lopes } \\
\text { Rodrigues - Feira de Santana }\end{array}$ & Direta & SESAB \\
\hline $\begin{array}{l}\text { Hospital de Ibotirama - } \\
\text { Ibotirama }\end{array}$ & Indireta - Terceirização & $\begin{array}{l}\text { SM - Assessoria Empresarial } \\
\text { e Gestão Hospitalar Ltda. }\end{array}$ \\
\hline $\begin{array}{l}\text { Hospital Eurídice Santana - } \\
\text { Santa Rita de Cássia }\end{array}$ & Indireta - OSS & $\begin{array}{l}\text { Obras Sociais Irmã Dulce - } \\
\text { OSID }\end{array}$ \\
\hline $\begin{array}{l}\text { Hospital Geral Deputado Luís } \\
\text { Eduardo Magalhães - Mairí }\end{array}$ & Indireta - OSS & PRÓ-Saúde \\
\hline $\begin{array}{l}\text { Hospital Regional de Castro } \\
\text { Alves - Castro Alves }\end{array}$ & Indireta - OSS & $\begin{array}{l}\text { APMICA - Associação de } \\
\text { Proteção à Maternidade e } \\
\text { Infância de Castro Alves }\end{array}$ \\
\hline $\begin{array}{l}\text { Hospital Regional de Juazeiro - } \\
\text { Juazeiro }\end{array}$ & Indireta - OSS & IMIP \\
\hline
\end{tabular}

Fonte: Elaborado pelas autoras, a partir de informaçôes cedidas pela Diretoria da Rede Própria sob Gestão Indireta (DIRPGI) - SESAB; Bahia (2013).

De acordo com CGI, até março de 2015, os dois únicos contratos por terceirização não seriam mais renovados e haveria seleção pública destes hospitais para publicização por OSS. Alguns estudos mostram que as experiências com OSS no Brasil apontam para maior flexibilidade e modernização na gestâo hospitalar pública, entretanto, 
com alta instabilidade e rotatividade de profissionais de saúde (MACHADO et al., 2016; IBANEEZ; VECINA, 2016), além de fragilidades no controle social, na integralidade e transparência (MELO et al., 2009).

Uma questão surgiu então: qual seria a motivação, o interesse, de uma empresa privada em gerir um hospital público, sem fins lucrativos? Para a CGI estas empresas pleiteavam "prestígio perante a sociedade". Para os diretores dos hospitais, uma questão de "amor", "vocação", "identificação", “envolvimento”, “desafio”.

Eu amo o que eu faço! E... Minha gestão eu não levo como esforço. Isso é um aprendizado (DG1).

[...] eu acho que é justamente o envolvimento... Eu não me vejo dentro de uma rede privada. [...] acho que é mais questáo de identificação com o serviço, entendeu? [...] E assim, uma OSS ela tem a capacidade de trazer pra esse universo público o que aprendeu do privado. É como se fosse uma missão (DA2).

Porém, além de toda a motivação abstrata, observou-se também motivação financeira. Apesar de os contratos com as OSS não contemplarem a taxa administrativa, como nos contratos terceirizados, havia remuneraçáo para o quadro da diretoria. Além da segurança estabelecida com o Estado, conforme explanado por DG2:

Primeiro, que a OSS náo tem lucro, mas os diretores podem ser remunerados. Eles têm um teto de remuneraçáo limitado a $70 \%$ do valor de um desembargador. [...] O que ela pode é remunerar a sua diretoria que trabalha. [...] aqui você tem garantias como, uma OSS não pode ir à falência, porque ela só vai à falência se for caracterizada má gestão. [...] se faltar algum recurso, o governo tem que aportar esse recurso para garantir a sobrevivência da instituição (DG2).

Segundo Gonçalves (1998), a maioria das OSS, que não dispóem de qualquer patrimônio ou estrutura hospitalar, ao efetuarem contratos (e não convênios) com o Estado, estaria atrás de benefícios pessoais para seus associados, que, de servidores públicos passariam a gestores da coisa pública (sem licitação ou concurso), obtendo salários melhores e outras vantagens. Vantagens estas que motivariam as empresas gestoras de hospitais com fins lucrativos a assumir a gestão desses hospitais, sob contrato por OSS, mediante recebimento de uma taxa administrativa.

Sabe-se que, além dos interesses econômicos e particulares envolvidos, o retorno do modelo das OSS, no bojo de um governo que sustentou discurso contrário às práticas de privatização, seja de bens, seja da gestão dos bens, envolve outras questôes políticas mais amplas que balizam a continuidade de discursos e práticas na gestão pública, antagônicas aos princípios que expressam o verdadeiro desejo da sociedade 
brasileira e que se encontra claramente expresso na sua Constituição: "a saúde é direito de todos e dever do Estado" (BRASIL, 1988).

\section{Considerações finais}

Os resultados deste estudo apresentaram a implantação das OSS na gestão da rede hospitalar do SUS, na Bahia. A paralisação da incorporação destas entidades, diante de fortes oposiçôes políticas ao processo, abriu espaço para a ascensão das terceirizações, a partir de 1996, mesmo sem uma legislação que autorizasse esse tipo de contrato jurídico. Nesse contexto, identificou-se o crescimento exponencial das OSS, no cenário hospitalar baiano, a partir de 2005, momento em que a oposiçáo política, no estado, ganhava terreno para o "velho carlismo"2 das décadas da ditadura militar.

A vitória do PT nas eleiçôes de 2006 trouxe um novo projeto de fundaçôes estatais que não conseguiu impor-se, cedendo espaço para o retorno das OSS como modalidade preferencial de gestão hospitalar na Bahia, a despeito dos discursos críticos de outrora. Na jornada de migração das terceirizaçôes para OSS, pôde-se visualizar um processo de brotamento de entidades a partir de OSS já consolidadas, em parceria com executivos, membros oriundos do ramo privado da construção civil. Estas novas entidades "camaleônicas", diante do ocaso das terceirizaçôes, mudaram sua identidade jurídica para atender ao novo discurso estadual da saúde, de que as OSS são "como se fosse o próprio Estado", pois estariam isentas de lucratividade nas suas práticas, discurso colocado em xeque pela evidência de alternância de cargos diretivos bem remunerados, entre as entidades.

O modus operandi das empresas lucrativas travestidas de Organização Social ainda não tem sido devidamente estudado no Brasil, mas pesquisas de autores europeus mostram a rapidez como o setor privado atua na penetração da esfera pública modificando sua cultura, relaçôes, manipulando a formulação de políticas públicas e sua implementação sob o olhar complacente da sociedade, seduzida pelo discurso da eficiência do setor privado e da corrupção do setor público e da própria transvaloração da noção de democracia e interesse público (SVALLFORS; TYLLSTRÖM, 2017; KAMAT, 2004).

Estados mais endividados e economicamente vulneráveis estão mais sujeitos à influência das diretrizes neoliberais que ordenam a diminuição do gasto público 
enquanto drenam os escassos recursos para o setor privado (REEVESA et alt., 2014). Nesse sentido, o papel do Banco Mundial na orientação das políticas da Secretaria de Saúde do Estado da Bahia já havia sido levantado por Coelho (2001), sem que haja indícios do arrefecimento desta influência nas novas gestôes do PT, como se observa no crescimento da modalidade PPP e da retirada gradual da União e dos estados no financiamento da Atenção Primária e das ações de Vigilância à Saúde.

Em especial, esse estudo aponta para o fortalecimento do CES como espaço autônomo e verdadeiramente representativo, pois veio de lá o único suspiro de crítica e indignação à inoperância dos controles sob a gestão hospitalar. Entretanto, o afrouxamento deste conselho nas deliberaçóes para as publicizaçóes e aditivos contratuais expressou a sua omissão com relação à política hospitalar na Bahia.

As limitaçóes que um estudo de caso oferece apontam para a necessidade de novas pesquisas no campo das políticas públicas que mostrem as diferenças de configuração em outros cenários organizacionais do Brasil e da América Latina, de um processo que se acredita não ser um mero fenômeno locorregional, mas indício de que as forças antagônicas à emancipação social não cessam de fluir e se transmutar, "como se fossem" exercício de justiça e democracia. ${ }^{3}$

\section{Referências}

ANDREWS, C. W; KOUZMIN, A. O discurso da nova administração pública. Lua Nova. São Paulo, n.45, p. 97-129, 1998.

BAHIA. Lei no 7027, de 29 de janeiro de 1997. Institui o Programa Estadual de Incentivo às Organizaçôes Sociais e dá outras providências. Diário Oficial [do] Estado da Bahia, Salvador, 30 jan. 1997a, p. 9-11.

. Decreto no 6480, de 13 de junho de 1997. Regulamenta a Lei no 7.027, de 29 de janeiro de 1997, que instituiu o Programa Estadual de Incentivo às Organizaçóes Sociais, e dá outras providências. Sistema de Legislação da Casa Civil, Salvador, 1997b.

. Decreto no 7007, de 14 de novembro de 1997. Regulamenta a Lei no 7.027, de 29 de janeiro de 1997, que instituiu o Programa Estadual de Incentivo às Organizaçóes Sociais, e dá outras providências. Sistema de Legislação da Casa Civil, Salvador, 1997c.

. Decreto no 7008, de 14 de novembro de 1997. Estabelece normas específicas para a operacionalização, pela área de saúde do Estado, do Programa Estadual de Incentivo às Organizações Sociais, instituído pela Lei no 7.027, de 29 de janeiro de 1997. Sistema de Legislação da Casa Civil, Salvador, 1997d. 
- Secretaria de Administração. O processo de modernização do Estado: Os avanços de uma década 1991-2001. Salvador: Universidade Federal da Bahia, Escola de Administração, 2002.

. Conselho Estadual de Saúde. Ata da 134º Reunião Ordinária. Salvador, BA, 31 out. 2007a. . Conselho Estadual de Saúde. Ata da 135º Reunião Ordinária. Salvador, 29 nov. 2007 b. . Conselho Estadual de Saúde. Ata da 139º Reunião Ordinária. Salvador, 27 mar. 2008. _. Conselho Estadual de Saúde. Ata da 159a Reunião Ordinária. Salvador, 16 dez. 2009. . Conselho Estadual de Saúde. Ata da 180a Reunião Ordinária. Salvador, 27 out. 2011. . Conselho Estadual de Saúde. Ata da 189a Reunião Ordinária. Salvador, 09 ago. 2012. . Secretaria de Administração. Manual de Constituição de Organizações Sociais. Salvador, 2004a, 46p.

- Decreto no 8.890, de 22 de Janeiro de 2004. Regulamenta a Lei no 8.647, de 29 de julho de 2003, que dispóe sobre o Programa Estadual de Organizaçóes Sociais, revoga os Decretos nos 7.007 e 7.008, de 14 de novembro de 1997, e dá outras providências. Sistema de Legislação da Casa Civil, Salvador, 2004 b.

. Lei n ${ }^{\circ} 8.647$ de 29 de julho de 2003. Dispóe sobre o Programa Estadual de Organizaçóes Sociais e dá outras providências. Sistema de Legislação da Casa Civil, Salvador, 2003.

. Secretaria de Saúde. Gestão da Rede Própria. Disponível em: <http://www.saude. ba.gov.br/novoportal/index.php?option=com_content $\&$ view=article $\&$ id $=8198 \&$ catid $=43 \&$ Ite mid=37>Acesso em: 15 ago. 2013.

BAHIA, P. I. V. C.; CARVALHO, P. M. Organizaçôes Sociais: qualificação como um ato vinculado do poder público. In: SÃO PAULO (Estado). Procuradoria Geral. Gestão compartilhada do serviço público e o tratamento constitucional do serviço público. São Paulo: CEPGES, [1998?]. Disponível em: <http://www.pge.sp.gov.br/centrodeestudos/bibliotecavirtual/Congresso/ wtese21.htm>. Acesso em: 02 fev. 2015.

BRASIL. Constituição da República Federativa do Brasil. Diário Oficial [da] República Federativa do Brasil, Brasília, DF, 05 out. 1988. Seção 1, p. 1-32.

. Ministério da Administração Federal e Reforma do Estado. Plano Diretor da reforma do aparelho do Estado. Brasília, DF, 1995, 68p.

. Ministério da Saúde. Cadastro Nacional de Estabelecimentos. Disponível em: <http:// cnes.datasus.gov.br/ > Acesso em: 15 nov. 2013.

- Tribunal de Contas da União. Relatório de auditoria operacional: transferência do gerenciamento de serviços públicos de saúde a Organizaçóes Sociais. Brasília, DF, 2012. 
. Lei no 8.666, de 21 de junho de 1993. Regulamenta o art. 37, inciso XXI, da Constituição Federal, institui normas para licitações e contratos da Administração Pública e dá outras providências. Diário Oficial [da] República Federativa do Brasil, Brasília, DF, 22 jun. 1993. p. 8269-8281.

. Lei no 9.637, de 15 de maio de 1998. Dispóe sobre a qualificação de entidades como organizações sociais, a criação do Programa Nacional de Publicização, a extinção dos órgãos e entidades que menciona e a absorção de suas atividades por organizaçóes sociais, e dá outras providências. Diário Oficial [da] República Federativa do Brasil, Brasília, DF, D.O. 18 mai. 1998. p. 8.

. Medida Provisória no 1591, de 9 de outubro de 1997. Dispõe sobre a qualificação de entidades como organizaçóes sociais, a criação do Programa Nacional de Publicização, a extinção do Laboratório Nacional de Luz Sincrotron e da Fundaçáo Roquette Pinto e a absorção de atividades por organizaçóes sociais, e dá outras providências. Coleção das Leis da República Federativa do Brasil, Brasília, DF, Imprensa Nacional, v. 189, n. 10, t. 1, p. 6529-6936, 1997.

COELHO, T. C. B. O Processo político de gestão em uma instituição complexa do Sistema único de Saúde. 2001. 233 p. Tese (Doutorado em Saúde Pública) - Instituto de Saúde Coletiva, Universidade Federal da Bahia, Salvador, 2001.

COSTA, F. L. da. Estado, reforma do Estado e democracia no Brasil da Nova República. Revista de Administração Pública. Rio de Janeiro, v. 32, n. 4, p. 71-82, 1998.

DANTAS NETO, P. F. Surf nas ondas do tempo: do carlismo histórico ao carlismo pós-carlista. Cadernos do CRH (UFBA), Salvador, v. 39, p. 213-255, 2003.

FAIRCLOUGH, N. Critical Discourse Analysis: the critical study of language. Londres: Longman, 1995.

GONÇALVES, W. Parecer sobre terceirização e parceiros na Saúde Pública. Rio Grande do Sul: Ministério Público. 1998. Disponível em: <http://www.mprs.mp.br/dirhum/doutrina/id239. htm> Acesso em: 10 dez. 2014.

GUIMARÃES, M. C. L. et al. Avaliação da capacidade de gestão de organizaçóes sociais: uma proposta metodológica. Cad. de Saúde Pública. Rio de Janeiro, v. 20, n. 6, p.1642-1650, 2004.

IBAÑEZ, N.; VECINA NETO, G. Modelos de gestão e o SUS. Ciênc. saúde coletiva. Rio de Janeiro, v. 12, p. 1831-1840, 2016. Disponível em: <http://dx.doi.org/10.1590/S141381232007000700006> Acesso em: 03 fev. 2018.

KAMAT, S. The privatization of public interest: theorizing NGO discourse in a neoliberal era. Review of International Political Economy, v. 11, n.1, p. 155-176, February, 2004.

KEINERT, T. M. M. et al. Delegação na prestação de serviços de saúde no estado da Bahia. In: Inovação e cooperação intergovernamental: microregionalização, consórcios, parcerias e terceirizações na saúde. São Paulo: Annablume, 2006. p. 123-126. 
LAURELL, A. C. A. Three decades of neoliberalism in Mexico: the destruction of society. International Journal of Health Services, v. 45, n. 2, p. 246-264, 2015.

MACHADO, C. V. Novos modelos de gerência nos hospitais públicos: as experiências recentes. Physis: Rev. de Saúde Coletiva, Rio de Janeiro, v. 11, n.1, p. 105-197, 2001.

MACHADO, C. V. et al. Gestão do trabalho nas Unidades de Pronto Atendimento: estratégias governamentais e perfil dos profissionais de saúde. Cad. Saúde Pública. Rio de Janeiro, v. 32, n. 2, 2016.

MAGALHÃES NETTO, J. M. Hospital público é terceirizado e recebe certificado ISO 9002. São Paulo: Folha de São Paulo, 11 de junho de 2000. Entrevista cedida a Marcos Vita.

MELO, C. M. M. et al. Avaliação da gestão terceirizada em uma unidade básica de saúde: resultados preliminares. Revista Baiana de Enfermagem, Salvador, v. 23, n. 1, 2, 3, p. 45-56, 2009.

O'LAUGHLIN, B. Pragmatism, structural reforms and the politics. Development and Change, v. 47, n.4, p. 686-711, 2016.

PEREIRA, C.G. O jogo entre elites e instituiçôes: As estratégias políticas de ACM Neto e a tradição carlista. Caderno CRH, Salvador, v. 30, n. 80, p. 237-255, 2017.

PINTO, I. C. M. Ascensão e queda de uma questão na agenda governamental: o caso das Organizaçóes Sociais da Saúde na Bahia. 2004. 255p. Tese (Doutorado em Administração de Empresas) - Escola de Administração, Universidade Federal da Bahia, Salvador, 2004.

REEVESA, A. et al. The political economy of austerity and healthcare: Cross-national analysis of expenditure changes in 27 European nations 1995-2011. Health Policy, v. 115, p. 1-8, 2014.

SANTOS, L. A. dos. O programa de publicização e as Organizaçôes Sociais. Livrozilla, 16 mar. 1998. Disponível em: <http://livrozilla.com/doc/672467/o-programa-depubliciza\%C3\%A7\%C3\%A3o-e-as-organiza\%C3\%A7\%C3\%B5es-sociais> Acesso em: 26 jan. 2015.

SIMONET, D. The New Public Management Theory in the British Health Care System: A Critical Review. Administration \& Society, v. 47 , n. 7, p. 802-826, 2013.

SOLLA, J. J. S. P. Fundaçóes Estatais de Direito Privado: projeto avança no Congresso e nos estados. Revista Radis, n. 79, mar. 2009.

Valorização profissional na pauta da secretaria. Jan/fev. 2007. Entrevista cedida à Revista Luta Médica, ano I, no 2, 2007.

SOUZA, P.C. de; SCATENA, J. H. G. Condiçôes de trabalho em hospitais do mix públicoprivado do Sistema Único de Saúde no Estado de Mato Grosso. Rev. Adm. Saúde, v. 16. n. 62, p. 33-40, 2014. 
SVALLFORS, S.; TYLLSTRÖM, A. Lobbying for profits: private companies and the privatization of the welfare state in Sweden. Stockholm: Institutet för framtidsstudier/Institute for Futures Studies, 2017 (Arbetsrapport/Working Paper 2017, n. 1).

WARING, J. Mapping the Public Sector Diaspora: towards a model of intersectoral cultural hybridity using evidence from the English healthcare reforms. Public Administration, v. 93, n.2, p. 345-362, 2015.

\section{Notas}

${ }^{1}$ Este trabalho é produto de dissertação de mestrado aprovada pelo Comitê de Ética em Pesquisa da Universidade Estadual de Feira de Santana em 2014.

${ }^{2}$ Carlismo é um fenômeno político iniciado na década dos anos 1970, no Estado da Bahia, em torno da forte liderança, por três mandatos, do governador Antônio Carlos Magalhães (ACM), que também ocupou o cargo de senador (1994-2002), presidente do Senado (1997-2011) e Ministro das Comunicaçôes (1985-1990). O carlismo, além de constituir forte liderança local e nacional por décadas, estabeleceu um modo de fazer política, hegemônico e ainda presente, caracterizado por uma combinação de modernização administrativa e política conservadora, clientelista e revanchista (PEREIRA, 2017).

${ }^{3}$ M. C. Reis foi responsável pela concepção do projeto de pesquisa; coleta, análise e interpretação dos dados; redação e revisão crítica do artigo. T. C. B. Coelho responsabilizou-se pela concepção do projeto de pesquisa; supervisão e orientação; análise e interpretação dos dados; redação e revisão crítica do artigo. 


\section{Abstract}

Publicization of hospital management in SUS: re-emergence of Health Social Organizations

The state of Bahia has been a "pioneer" in privatization of hospital management through a policy of encouraging Health Social Organizations (OSS) under the discourse of greater efficiency. The rapidity as the private sector penetrates the public sphere and modifies the notion of democracy and public interest has been noted around the world. To analyze the process of OSS management in two cases, documents available in the public domain sites and interviews with the hospital and the Health Department of Bahia State (SESAB) management staff were used. A comparison between the data collected by different sources was supported by historical and operational-analytical categories which allowed its interpretation and showed the rise of outsourcings since 1996, and the emergence of OSS in the Bahia hospital scene from 2005 forward, side by side with the weakness of the Health State Council control and the revival of the "best efficiency" discourse that would be "almost like the state." To meet the new policy and tune up with the new government discourse, ex-outsourced companies changed their legal personality to OSS. Such disguised privatization process was protagonized by a government that supported contrary speech about this practice antagonistical to the principles of health security, expressed by the Brazilian Constitution.

Keywords: health management; hospital administration; outsourced services. 